\title{
Conmemoraciones e historiografía
}

\section{Commemorations and historiography}

Francisco Quiroz Chueca

Universidad Nacional Mayor de San Marcos

\section{RESUMEN}

Las celebraciones nacionales son momentos propicios para el jubileo, pero también para pensar y repensar los hechos y sus consecuencias. Por lo común, se estudian las conmemoraciones desde el punto de vista político y hasta estético (fiestas, monumentos, discursos). Este artículo sostiene que las conmemoraciones son importantes también por los debates que la sociedad sostiene en torno al significado y las consecuencias de los hechos que se conmemoran. Para esto, se elige la historiografía, por ser un discurso que refleja las tendencias sociales y étnico-culturales de una colectividad, y las tensiones ideológicas que subyacen a las ideas de nación que están en controversia. Se analiza el caso de las celebraciones por aniversarios de la Independencia y la correspondiente discusión historiográfica más significativas de nuestra trayectoria independiente y republicana.

Palabras clave:

Palabras clave: Perú bicentenario, conmemoración, memoria histórica, historiografía, nación

\section{ABSTRACT}

National celebrations are suitable moments for festivity but also for thinking and rethinking historic events and their consequences. Commemorations are usually studied from the political and even esthetical point of view (parties, monuments, speeches). This article supports the fact that commemorations are also important due to society's debates around the meaning and consequences of the commemorated events. For this, historiography is chosen because it is a discourse that reflects the social and ethnic-cultural tendencies of a community, and the ideological tensions that underlie the controversial ideas of nation. This article analyzes the celebrations of the Independence Day and the most important historiographical discussions of our independent and republican tradition.

\section{Keywords:}

Keywords: Bicentennial Peru, commemoration, historical memory, historiography, nation 


\section{Introducción}

U na sociedad moderna requiere conmemorar hechos históricos fundacionales con el fin de afirmar y reafirmar las bases de su identidad como nación estableciendo discursos hegemónicos dirigidos a ser impuestos como la versión, digamos, oficial para el consumo de toda la nación, tarea muy complicada en un país culturalmente megadiverso como el Perú. Es decir, se va mucho más allá de las ceremonias celebratorias y, más bien, se reflexiona sobre el significado de los hechos y sus consecuencias. Quien conmemora no es un país en abstracto, sino una sociedad concreta con características determinadas. Esto lleva a la necesidad de estudiar las conmemoraciones teniendo en cuenta los componentes de la sociedad y las versiones de la historia que dan cuenta del significado de los hechos que serán conmemorados.

El hecho es que la Independencia de $1820-1826$ es un tema muy controversial, tanto para los historiadores como para la sociedad peruana. Al igual que otros temas de la historia, la Independencia es asumida de diferentes maneras por los sectores sociales y etnoculturales, las regiones del país y por la historiografía.

Este artículo busca establecer las condiciones sociales y los debates historiográficos en los que el país afronta los aniversarios clave de la Independencia a fin de entender las interpretaciones dadas y las propuestas sobre el rumbo que toma el país a raíz de un hecho de tanta importancia para este y nuestra nación, en vísperas de un nuevo e importantísimo jubileo: el bicentenario.

Las celebraciones bajo análisis y la correspondiente discusión historiográfica más significativas, por ser momentos especiales de nuestra historia, son las siguientes: 1846 (primer cuarto de siglo), 1871 (primer medio siglo), 1921 (centenario), 1971 (sesquicentenario) y 2021 (bicentenario)'

\section{La historiografía en la Independencia}

Nuestra historiografía siempre ha sido controversial. Al menos, la conocida desde el siglo xvı (si no antes) se ha desenvuelto siempre a manera de propuestas y respuestas, y los hechos de la separación política no son una excepción sino, antes bien, una reafirmación de lo dicho. A la versión oficial de la historia imperial española del siglo xvı (los cronistas de Indias), el Inca Garcilaso de la Vega opuso una versión andina incaísta-encomendera en sus Comentarios reales de los incas (1609-1617). A esta interpretación, se opuso toda una pléyade de autores laicos y religiosos denominados como el patriotismo criollo a lo largo del siglo xvı y que Pedro Peralta Barnuevo resume en su versión limeñista criolla en Lima fundada (1732). A esta interpretación, se opone la versión imperial que la monarquía borbónica quiso y logró imponer a partir de la Real Academia de la Historia de Madrid en la segunda mitad del siglo XVIII y que se consagra como versión oficial de los criollos peruanos con Cosme Bueno (1763), el oidor Cerdán de Landa en el Mercurio Peruano (1791-1795) e Hipólito Unanue en la Guía (1793-1797). La primavera liberal de Cádiz no genera una versión histórica contestataria entre los criollos peruanos y la nueva primavera del trienio liberal español produce tan solo una leve y vaga oposición al legado colonial español en los Andes como sustento del rompimiento político. Luego de la Independencia, se retoma el carácter controversial de la historiografía peruana con la sucesión y convivencia de interpretaciones ${ }^{2}$, que es lo que a este artículo le interesa.

De hecho, la historia que manejan y aceptan las élites criollas hacia las postrimerías del período colonial es una historia del Perú como parte del imperio español, y esto afecta muy directamente la discusión ideológica en tiempos de la separación política a partir de 1809 y durante la prolongada guerra separatista y el largo proceso de establecimiento de la institucionalidad independiente y republicana.

Los hechos que conducen en los Andes a la Independencia permiten dudar acerca de la decisión de los sectores propietarios por separarse del Imperio español. Esto se refleja claramente en los argumentos históricos esgrimidos en los debates ideológicos y las luchas políticas de las décadas de 1810 y 1820, durante las que se produce la separación efectiva. Los periódicos publicados durante las Cortes de Cádiz y del trienio liberal español muestran que el rechazo histórico al colonialismo no es un argumento clave en las discusiones políticas e ideológicas. 
En efecto, los criollos peruanos carecen de la decisión y audacia para apropiarse de la historia prehispánica y declarar abiertamente que el tiempo español fue muy negativo. En el Perú, estas manifestaciones antiespañolas son muy moderadas y giran en torno de lo que llaman vagamente la tiranía y el despotismo de tres siglos, dichos en su mayor parte en contextos en los que son los criollos los protagonistas de las acciones.

El mismo sesgo se advierte en las escasas referencias a los hijos del Sol, que bien podrían remitir a los descendientes de los incas (o incluso a los indios), pero por el contexto en que aparecen es claro que son los propios criollos quienes se llaman así a falta de otros referentes históricos, en el fragor de los debates más bien políticos e ideológicos entre periódicos sanmartinianos como El Pacificador del Perú, El Americano o Los Andes Libres (1821) y El Sol del Perú (1822-1823) y sus pares leales al régimen español (Rosas Lauro, 2005) ${ }^{3}$.

En realidad, para los criollos peruanos (sobre todo desde Lima), el referente más preciso del país son la geografía y sus riquezas antes que la sociedad, su historia y su futuro (misión o destino como nación). No es casual que el escudo nacional creado por los criollos en Lima tenga referencias a la riqueza material y no a su riqueza histórica.

La Independencia es, sin duda, uno de los hitos centrales de nuestra trayectoria histórica al crear un Estado nuevo con un régimen político nuevo y, entonces, muy novedoso, como lo es la república. Más que por los cambios en sí, la Independencia es crucial por las posibilidades de cambio que significaba para los diferentes sectores de la población. Jorge Basadre llamó con razón a estas expectativas la promesa de la vida republicana.

\section{Hacia el primer cuarto de siglo}

Tanto el nuevo Estado independiente como el régimen político republicano y representativo se inician en el Perú sin un debate historiográfico que justifique los cambios.
La timidez del rompimiento político y de los cambios estructurales de la sociedad, economía y cultura pueden dar cuenta de esto, pues en el proceso, las élites sociales no llegan a cuestionar el sistema colonial a partir de una historia alternativa que señale lo negativo que había sido el tiempo colonial como para justificar su destrucción y su sustitución por otro mejor.

Debió ser difícil plantear esto en tiempos inmediatos a la separación. No tanto por lo reciente de los hechos cuanto porque no era posible realizar afirmaciones categóricas acerca de la decisión separatista de las élites criollas peruanas estando como estaban humeando todavía los hechos que la contradecían. Pero también es central el hecho de que la anarquía política, las guerras externas, los problemas económicos y la falta de cambios sociales significativos impedían concluir que la separación estaba dando sus frutos superando largamente el régimen anterior.

Sin embargo, de todas maneras, se produce una discusión historiográfica cuyo eje es el tiempo del dominio colonial por ser ineludible al momento de justificar la separación y, sobre todo, establecer la superioridad del momento independiente sobre el colonial. Sin embargo, en el debate se manifiesta también la tendencia a revalorar el tiempo español de cara a mantener el hispanismo y el catolicismo como fuentes de la identidad de los sectores criollos conservadores. Cuatro textos buscan dar cuenta de lo ocurrido justificando la ruptura política y evaluando de manera diferente el lugar de España y del colonialismo español: a) críticos del colonialismo fueron el liberal cusqueño José Manuel Valdez y Palacios (1844, en portugués) y el coronel celendino Juan Basilio Cortegana (1844-1848, inédito hasta hoy); b) ambiguo en sus críticas fue el funcionario limeño José María Córdova Urrutia (1844), y c) justificador del colonialismo fue el sacerdote Bartolomé Herrera (1846).

Los cuatro narran la larga trayectoria peruana que confluye en la Independencia dando a entender lo progresivo del curso de nuestra historia, pero con fundamentos y fines diferentes. En traducción castellana de

3 Más bien, son muy pocas las alusiones directas a hechos históricos que justifiquen la separación. “Reflexiones sobre la independencia del Perú" es un texto que proporciona detalles de la opresión colonial, fue publicado en el periódico Los Andes Libres (julio de 1821, inmediatamente luego de la proclamación de la Independencia). El autor, que bien pudo ser el cusqueño José Manuel Valdez y Palacios, sigue al Inca Garcilaso en su Historia general del Perú para mostrar los horrores de la conquista y a Viscardo Guzmán para justificar la necesidad de emanciparse. De todas maneras, el centro de atención del autor es la resistencia criolla más que la indígena o mestiza (Tauro, 1971, pp. 261-265, pp. 267-271, pp. 279-283, pp. 287-290). También se dirige a los criollos el autor que se esconde tras el acrónimo"J. E. B" en los versos de un "Himno patriótico" publicado en el mismo periódico en septiembre de 1821. Su alusión a la tierra de los "Incas peruanos" es más una referencia geográfica del país donde los "Hijos del Sol” (criollos) han sufrido las "cadenas de impío opresor", pero que ahora ya disfrutan de libertad al jurar Lima la Independencia (Tauro, 1971, p. 300). 
1971, el texto de Valdez y Palacios se llama Bosquejo sobre el estado político, moral y literario del Perú en sus tres grandes épocas ${ }^{4}$, mientras que el de Córdova Urrutia se denomina Las 3 épocas del Perú o compendio de su historia (1844) $[1845]^{5}$.

Uno de los puntos centrales de esta generación de historiadores será la creación del concepto de precursores. Valdez y Palacios (1971) y otros autores hacen la separación entre los líderes anteriores (mayormente, indígenas y mestizos) como Farfán de los Godos, Túpac Amaru, Aguilar y Ubalde, los Angulo, Pumacahua y otros que realizaron esfuerzos separatistas, pero no como "resultado de grandes combinaciones políticas, ni el efecto de la disposición de masas", sino "la consecuencia de la opresión llevada al extremo" (pp. 65-66). Córdova Urrutia rechaza más tajantemente las manifestaciones rebeldes anteriores, especialmente la de Túpac Amaru. Todo esto sirve para resaltar el papel que tuvieron los criollos $y$, eventualmente, el papel de Lima en la lucha.

El otro punto central en las versiones históricas es el jugado por San Martín, Bolívar y los peruanos en la guerra separatista y la formación del nuevo Estado. Si para Córdova Urrutia el protagonismo lo tuvo San Martín y, de su lado, pinta a Bolívar como el dictador del Perú; para Valdez y Palacios, la Independencia fue obra del ejército de Bolívar. Más bien, Cortegana escribe su historia con ánimos de rectificar las versiones oficiales y reivindicar el papel primordial de los soldados y oficiales peruanos en la gesta.

Es más, Valdez y Palacios tiene en pésima estima la actuación de las élites limeñas y Cortegana afirma que los criollos de la "clase influyente" de la capital son "inmorales, corruptos y traidores" (Carrasco Limas, 1954).

Como se ve, Lima tenía todavía serios competidores que le impedían imponer sus versiones de la historia peruana. Este centralismo historiográfico se inicia cuando las élites peruanas (especialmente, las radicadas en Lima) tienen éxito económico gracias a las exportaciones de guano desde 1840 y logran controlar las riendas del poder político y social en tiempos de Ramón Castilla (desde 1845).

En efecto, el Perú cumplía un cuarto de siglo de vida independiente cuando se empiezan a ver los frutos de la pax castillista. Interesaba a esos sectores dominantes contar con una historia menos conflictiva y más proactiva con respecto al legado español y cristiano (versus el legado anglosajón y protestante que se introducía con fuerza). La oportunidad la brinda el mismo presidente Castilla al invitar el 28 de julio de 1846 al sacerdote ultraconservador Bartolomé Herrera a dar el discurso central en el tedeum por los veinticinco años de la proclamación de la independencia. Herrera modifica el criollismo limeño-centrista de Peralta Barnuevo para dar cabida a un Perú español sin España, y al aceptar la Independencia, la República debe rectificar los principios falsos de la Revolución francesa que supone guiaron a los libertadores. Ahora, se debe conducir el país sin excesos inclusivistas y, en particular, descartar al indígena como ciudadano (la doctrina herreriana de la soberanía de la inteligencia).

Herrera aprovecha para establecer los parámetros de la historia peruana en términos nuevamente providencialistas al hacer depender todo el devenir del Perú de la voluntad de Dios. Los españoles y su régimen no podían ser malos, pues ellos solo ejecutaron los designios divinos para la evangelización de los pobladores de los Andes. Desde ya, para Herrera, la historia del Perú se inicia con la conquista europea. Pero el aspecto que interesa en particular es que Herrera asume - sin mencionarla - la doctrina que expone el jesuita Juan Pablo Viscardo y Guzmán en su famosa Carta a los españoles americanos (en 1798 en francés y en 1801 en castellano): la separación fue más un hecho biológico de madurez y emancipación antes que un hecho violento de independencia. De ahí que la separación sea vista como un acto de toma de conciencia del ser nacional por parte de la población guiada por los esclarecidos criollos. Con esto, Herrera pone los cimientos ideológicos de una interpretación de la Independencia que tiene una vigencia muy larga en nuestra historiografía.

4 Aunque cusqueño, Valdez y Palacios ignora la historia prehispánica y empieza con la colonia para pintar un cuadro negativo debido a los monopolios comerciales, el despilfarro de las riquezas extraídas, los elevados impuestos, la codicia en la minería y la "opresión mental". Precisamente, la superación de todas estas trabas es el contenido de la corta historia que cuenta Valdez y Palacios después de la Independencia (1971, p. 80).

5 La versión de Córdova Urrutia es más inclusiva, pero por haber glosado irreflexivamente versiones anteriores (inclusive versiones contradictorias entre sí), y empieza con el imperio incaico, sigue con la "dinastía ultramarina" y termina en el "Perú independiente". Su enfoque por gobernantes otorga continuidad a la historia peruana al considerar a incas, reyes españoles y presidentes por igual. Por querer dar el lado positivo en todo el devenir histórico, Córdova Urrutia debe recurrir a explicaciones providencialistas ya superadas en el siglo anterior en la historiografía peruana. 
La gran conclusión del texto es que el Perú es un país occidental y cristiano creado por la conquista, lo que satisfacía plenamente a las élites progresistas de la república guanera ${ }^{6}$.

\section{Medio siglo de república independiente}

El apogeo del negocio guanero consolida a una oligarquía limeña comercial, bancaria y agroexportadora que controla el Estado y vive convencida de que el país está en camino a integrarse a la civilización occidental, que se identifica con el ferrocarril, el telégrafo y las modas en el vestir, pero no con el cambio social, la extensión de los derechos civiles y la integración del espacio nacional. El país es líder político, militar, económico y cultural en Sudamérica. La exposición de 1872 es reflejo de esta tendencia.

Desde la perspectiva historiográfica, el medio siglo de vida independiente se adelantó un poco, pues ocurre un hecho que ha de marcar la reflexión en torno al significado de la Independencia y el legado del colonialismo en nuestra historia: el intento de España por recuperar sus antiguas colonias sudamericanas en el periodo 1863-1866 y que culmina en el combate del Callao el 2 de mayo de 1866. La invasión española genera un sentimiento antiespañol y anticolonialista que se refleja en la historia.

La tarea central era demostrar el protagonismo de Lima en la Independencia y en la creación del Estado nación moderno; es decir, ya no solamente mencionar el papel de Lima y los criollos, sino afirmar que tuvieron un papel crucial como guía y ejecutores de la guerra separatista, sin desmerecer la participación de extranjeros. Con el negocio guanero, el Perú se había convertido en un país extremadamente centralista y ahora quedaba dictar la historia a las provincias y a los sectores sociales y étnico-culturales.

En ese contexto, aparecen dos versiones de la historia que bien pueden ser consideradas como nacionalistas y ligadas a la construcción del Estado nación. Sebastián Lorente y Mariano Felipe Paz Soldán tienen —cada quien por su lado- una visión de conjunto de la historia del Perú en relatos orgánicamente estructurados. Ambos pretenden presentar la trayectoria histórica del país para mostrar sus logros actuales como país civilizado en el contexto de la modernidad del siglo xIx. Pero sus propuestas difieren mucho entre sí.

Sebastián Lorente -liberal español afincado en el Perú- es el autor de un nuevo modelo interpretativo de la historia peruana: una visión integradora, inclusiva, reivindicativa, en un enfoque historicista que da continuidad a la historia peruana en una evolución milenaria y progresiva.

Lorente parte de los aportes de Mariano de Rivero y del suizo Juan Jacobo von Tschudi (Antigüedades peruanas, $1841,1851)$ sobre lo preincaico, y lo incluye junto con lo incaico en la historia peruana como momentos constitutivos de la nacionalidad. Sin embargo, la posición de Lorente no es igualitaria. Antes bien, Lorente encuentra en la historia antigua los vínculos que pueden ayudar en la tarea de civilizar a la población nativa a fin de que pueda ser parte de la civilización peruana en el contexto de la civilización occidental. Este elemento vinculante es lo que él llama el socialismo teocrático incaico y que consiste en el despotismo de los incas que hacía que todo funcione apropiadamente en el Tahuantinsuyo. La construcción de un Estado nación según Lorente debería considerar el ascendiente de los líderes indígenas para garantizar la solidaridad y la armonía social que debe ser aplicada en el Perú contemporáneo para la creación de una sociedad moderna guiada por los crioIlos (Lorente, 2005, pp. 55-56; Lorente, 1879, p. 5).

Para Lorente, de otro lado, el tiempo español aporta positiva y negativamente a la nacionalidad. Como liberal, es claro que condena las restricciones políticas, económicas, sociales, culturales y la intolerancia religiosa (tiranía y oscurantismo). Pero también reconoce, con su amigo Bartolomé Herrera, el papel que cumple la civilización española en la formación de la civilización criolla peruana. Para Lorente, entonces, el legado español es ambiguo y, no siendo rechazado, termina

6 Esta visión, políticamente conservadora, sigue su curso en la historiografía peruana (sobre todo, en la limeña), que de manera creciente tiene en lo colonial español un tema central de sus intereses. Es cierto que la visión histórica de Herrera tendrá que esperar el siglo siguiente para alcanzar su aceptación y desarrollo por la historiografía hispanista, pero ya en el xIx se reivindica la historia colonial luego de haber sufrido las inclemencias de las batallas ideológicas durante la guerra separatista. Historiadores nacionalistas como Manuel de Odriozola, Manuel de Mendiburu, Manuel Atanasio Fuentes, Sebastián Lorente, José Toribio Polo, y literatos como Ricardo Palma y colaboradores de la Revista de Lima (1859-1863, 1873), tendrán lo colonial como parte muy importante en la formación de la nacionalidad peruana. 
siendo aceptado como parte muy importante de la nacionalidad peruana. La Independencia es vista como un momento de madurez, necesario para el desarrollo ulterior del Perú en el marco de la civilización occidental y católica. Lorente es uno de los creadores principales del mito de Ramón Castilla como el mejor presidente del país, al vincular con él el establecimiento del orden y del progreso material y cultural del Perú luego de la Independencia.

De su lado, Mariano Felipe Paz Soldán consolida la historia criolla del Perú. Paz Soldán establece que la Independencia de 1821 es no solamente el acontecimiento más importante, sino sobre todo el hito fundador del Perú moderno (1868-1874). Negando lo prehispánico y lo colonial como momentos históricos errados, Paz Soldán traza líneas de desarrollo del Perú en función de su incorporación al mundo occidental contemporáneo. Paz Soldán es claro al identificar el Perú con la cultura criolla que crea un Estado moderno en tiempos del guano. Es más, Paz Soldán identifica la nación peruana con el Estado peruano.

No por casualidad, la alta sociedad de entonces (e historiadores posteriores) consideran la historia nacional peruana de Paz Soldán como la más apropiada para entender el país como una nación.

\section{El centenario}

El Perú llega al centenario de la Independencia en condiciones muy especiales que inclusive hacen variar el contenido de este evento: se conmemoran dos fechas y no una. Además de la fecha aceptada del 28 de julio, se celebra también la batalla de Ayacucho (1924). Esto no se presenta como casual. Veamos por qué.

La llamada era del guano o era del guano y del salitre acaba de manera catastrófica en la guerra con Chile (1879-1883), en la que el Perú, arrogante y enlistado ya entre los países civilizados del momento, es derrotado de manera contundente por las armas, mutilado en su territorio, destruido políticamente por su propia incapacidad y humillado en su orgullo nacional por un país como Chile, al que históricamente consideraba no solo subordinado y dependiente, sino también muy inferior en todos los aspectos.

La reconstrucción fue penosa en lo político (nuevo caudillismo militar y civil), lo económico (Contrato Grace, reforma tributaria y nuevos enfoques en las inversiones), lo social, lo cultural y lo identitario. Lejos de superar el régimen oligárquico y hasta plutocrático, centralista y egoísta que condujo a la debacle de 1879 , el país es reconstruido nuevamente con otro régimen oligárquico que es el dominio de un puñado de familias oligárquicas de la costa y el control de la sierra por los llamados gamonales. La reconstrucción económica se basa en nuevas actividades exportadoras de mucha mayor magnitud que antes de la guerra y está en manos de peruanos y grandes empresas extranjeras (azúcar, algodón, lanas, caucho, minería, hidrocarburos). La orientación política y social proinglesa y la exclusión de los indígenas, en 1896, de la ciudadanía le dan el nombre de República Aristocrática (1895-1919).

Dentro de la oligarquía surge un sector, digamos, progresista. Progresista tanto por buscar modernizar el país en términos de los nuevos tiempos, como también por buscar inclinarse hacia la economía norteamericana, vencedora de la Gran Guerra de 1914-1918, frente al capitalismo ya obsoleto que representaban Gran Bretaña y Francia. En parte, esta tendencia tiene un componente reivindicativo provinciano frente a la capital siempre centralista. Dos personajes visibles en estas tendencias modernizantes son Guillermo Billinghurst y, sobre todo, Augusto B. Leguía.

Típico de la oligarquía es la desilusión republicana. No rechaza la Independencia, sino sus resultados a largo plazo. La República estorba pues, al menos, de manera nominal, exige la consulta popular de tiempo en tiempo poniendo en peligro el mando del país en tiempos en que la economía exportadora había generado diversas actividades colaterales en servicios e industria moderna, así como un sector social medio de técnicos y profesionales, y el fortalecimiento del Estado había creado una nueva y más amplia burocracia civil y militar. Nuevos sectores sociales cuestionan el sistema oligárquico y hasta llegan a plantear alternativas autónomas bajo banderas indigenistas, anarquistas, socialistas, liberales y populistas (Sanders, 1997).

La euforia de la oligarquía por presentarse como abanderada de la modernidad a un siglo de vida independiente, y superado el traspiés de la guerra con Chile, se ve afectada por las ideas cuestionadoras de las nuevas tendencias ideológicas, sociales, políticas y culturales. Sectores populares y medios logran replantear los términos del debate nacional. El mismo régimen político se verá interrumpido por el gobierno de Billinghurst (1912-1914) y, sobre todo, por el triunfo electoral de Leguía en 1919, en medio de manifestaciones populares en ciudades y haciendas, y que declara la denominada Patria Nueva como programa de recambio dentro de la oligarquía. 
La oligarquía tradicional, falta de propuestas alternativas creativas y eficaces para mantener su predominio ideológico, presenta, sin embargo, dos proyectos que buscan superar el vacío: Francisco García Calderón y José de la Riva Agüero y Osma. Uno sustenta la necesidad de sustituir la república por un régimen dictatorial (cesarismo democrático); otro presenta el mestizaje como idea-fuerza de la nacionalidad peruana.

Al lado de otros intelectuales latinoamericanos desengañados de la trayectoria republicana, Francisco García Calderón se empeña en una alternativa autoritaria pasando por alto los inconvenientes de la representación y la democracia. En sus ensayos El Perú contemporáneo (1907) y Las democracias latinas de América (1912) publicados en francés, pero con amplia circulación entre la intelectualidad peruana y latinoamericana, fundamenta ideas que posteriormente otros intelectuales también han de desarrollar acerca de la misión histórica que tiene la élite intelectual y política latinoamericana apoyando regímenes autoritarios y hasta dictaduras abiertas.

De su lado, José de la Riva Agüero y Osma rechaza a los caudillos plebiscitarios que sustituyen la representación popular, pero - partidario de la monarquía - prefiere un régimen capaz de controlar a los nuevos sectores sociales y étnico-raciales. Para esto, encuentra la fórmula perfecta en una interpretación de la historia peruana que resalta la conformación de un pueblo mestizo desde la conquista europea. Parte de las ideas de Bartolomé Herrera sobre un nuevo país creado por la conquista, pero su conclusión es que el país es nuevo por no ser ni indígena ni español. El gran paradigma de ese nuevo país será el Inca Garcilaso de la Vega. Como resultado de una polémica historiográfica sobre la originalidad de la obra del gran autor cusqueño (1908-1912), José de la Riva Agüero (1938) descubre en Garcilaso la imagen del mestizo que otros posteriormente proyectan a toda la nación peruana.

Para las conmemoraciones (1921-1924), sin embargo, prima la historiografía oligárquica que ya se vislumbraba antes de la guerra. En efecto, Herrera, Lorente y Paz Soldán siguen vigentes en una suerte de convivencia por conveniencias, pues el centenario no cuestiona el legado español, sino glorifica los hechos de los libertadores. Es decir, el colonialismo no era un problema (Herrera), se reivindica la cultura prehispánica y española
(Lorente) y, sobre todo, la gesta heroica de la separación es el principal contenido de nuestra historia patria (Paz Soldán). El heroísmo se acrecienta con las dos grandes gestas posteriores: la defensa del país ante la amenaza española (1863-1866) y la guerra con Chile (Casalino Sen, 2008). Este contexto subraya un mayor reconocimiento de la participación peruana en los hitos fundamentales de nuestra historia como sustento de la nacionalidad peruana. Esta es la base para un nuevo cambio historiográfico a partir del centenario?.

Sin embargo, no todo fue concordia y coro uniforme, pues desde ya no es San Martín el único protagonista de la Independencia y, más bien, se debe reconocer a Bolívar el papel de conductor de la gesta en los momentos decisivos (en especial, las definiciones militares en su campaña a la sierra en búsqueda del ejército virreinal y sus victorias en Junín y en Ayacucho en 1824). Sin embargo, si Bolívar no fue totalmente reivindicado en la historiografía peruana, sí adquiere un estatus de tolerancia por ser la oligarquía más inclinada a la conciliación hegemónica que a la historia conflictiva.

La disidencia más interesante proviene de un ámbito inusitado y de otro esperable. El empresario Pedro Dávalos Lissón publica un conjunto de comentarios propios y ajenos en cuatro volúmenes que titula $L a$ primera centuria, pero que lleva como subtítulo "Causas geográficas, políticas y económicas que han detenido el progreso moral y material del Perú en el primer siglo de su vida independiente" (Dávalos Lissón, 1919-1926). El tono pesimista da cuenta del desencanto de los grupos de poder en cuanto al régimen que condujo al desastre nacional (guerra con Chile) y a la "liquidación de valores morales y materiales" y a "las teorías democráticas [que] eran irrealizables en el Perú" (IV, pp. 89-90).

A cien años de república representativa y nominalmente democrática, el régimen oligárquico del país contrastaba fuertemente con la situación que debería tener el país. Esta situación es planteada por nuevos comentaristas y analistas que no pertenecen a la oligarquía y hasta se le oponen. Esto es algo importante, pues prácticamente hasta ese tiempo la oligarquía había tenido casi el monopolio de la opinión. El indigenismo y, sobre todo, el pensamiento crítico de José Carlos Mariátegui, se presentan como una alternativa al pensamiento dominante. Mariátegui (1928) plantea directamente

7 Germán Leguía y Martínez (1972) reivindica la participación y hasta el protagonismo de peruanos en la Independencia en su detallado estudio del protectorado de San Martín. 
que la Independencia fue un hecho no deseado por las élites sociales peruanas y se dio solo por la intervención de extranjeros. Además, Mariátegui señala más continuidades que cambios radicales. Estas ideas serán esgrimidas medio siglo después en el sesquicentenario y guiarán los estudios de la historia de la Independencia y la república (pp. 46, 66-69).

Mientras tanto, la historiografía conservadora se impone con dos tendencias muy importantes, complementarias entre sí, derivadas de las ideas de Viscardo y de Herrera sobre la Emancipación (no Independencia) y de Riva Agüero sobre el mestizaje como componente principal de la nacionalidad peruana.

\section{Sesquicentenario}

El sesquicentenario encuentra al país en la crisis del régimen oligárquico y los diversos intentos por superarlo y enrumbar al Perú por una senda democrática y de desarrollo moderno. Fracasada la opción democratizadora de sectores medios radicales (APRA) y moderados (Acción Popular y Democracia Cristiana), un grupo de militares antioligárquicos y nacionalistas busca realizar a su manera las reformas que el país necesitaba. El régimen militar de Juan Velasco Alvarado y las Fuerzas Armadas ve en el sesquicentenario de la Independencia la oportunidad de resaltar la importancia de los cambios que hacía presentándolos como la segunda independencia, esta vez, la independencia económica. Pero, además, fue también importante la necesidad de cambiar la interpretación oligárquica de la historia peruana vigente entonces: la historiografía conservadora (llamada habitualmente tradicional y hasta positivista).

Se dijo anteriormente que la historiografía conservadora parte de las ideas de Viscardo y de Herrera, y de Riva Agüero. La urgencia de una versión oficial está en la necesidad de responder a las disidencias que se presentan en la intelectualidad y en las alternativas políticas antioligárquicas y populares a partir de la década de 1920, que usan precisamente un discurso histórico para justificar el cambio social en el país en medio de dictaduras que preservan el estatus oligárquico.
No debe extrañar, por eso, la elaboración de propuestas intelectuales muy sofisticadas para la ocasión. Víctor Andrés Belaúnde replica directa e inmediatamente a José Carlos Mariátegui en La realidad nacional (1930 [1929]). La opción de Belaúnde es claramente autoritaria. Para él, la trayectoria del país enseña que solo en tiempos de gobernantes como Ramón Castilla o Nicolás de Piérola se ha podido mantener el orden en un país que se tornaba cada vez más difícil de manejar. En efecto, en un texto anterior, Meditaciones peruanas (1933 [1917]), Belaúnde se coloca abiertamente del lado de la doctrina de la soberanía de la inteligencia de Bartolomé Herrera como la respuesta a la que se debe acudir en el dilema de la vigencia de la república. Aquí, Belaúnde afirma que la práctica y la ciencia han demostrado "las mentiras de la revolución" $\mathrm{y}$ "han desvanecido muchas de las ilusiones de la exagerada democracia por lo absurdo del igualitarismo político en un pueblo, como el nuestro, de tan complicada estructura" (1987, Il, pp. 100-101). La solución es la formación de una oligarquía intelectual de hombres de posición y de talento, de virtud (1987, II, p. 128) que guíe a un pueblo étnicamente mestizo. Esto último —el mestizaje- es tenido como la idea que guía el rumbo de nuestra nacionalidad que se inicia con la conquista europea.

Precisamente, la conquista europea será el punto de partida de la historia peruana en su versión conservadora. Es el padre Vargas Ugarte el creador de una versión de la historia peruana que tendrá (y tiene) amplia vigencia. Haciéndose eco de lo exigido por Bartolomé Herrera, el foco de interés de la historiografía debe ser el Perú a partir de la conquista ${ }^{8}$. Siguiendo a Viscardo y a Herrera, Vargas Ugarte encuentra que, a pesar de las restricciones que el hecho colonial significaba para el desarrollo de los criollos, estos logran una madurez política, económica, social e intelectual que los faculta a emanciparse del tutelaje de su madre (metrópoli), y esta mayoría de edad intelectual se refleja en las páginas del Mercurio Peruano (1791-1795). Es decir, la nación peruana precede a la Independencia?

Además, esta versión de la historia de la Independencia es criollista y nacionalista. Para Vargas Ugarte, los criollos lideran la separación mientras que los demás componentes sociales y étnico-culturales se incorporan

8 Afirma Vargas Ugarte que los cursos de historia del Perú deben comenzar "por el estudio de la Conquista, ameno e interesante y con el cual, lógicamente, empieza el verdadero Perú, nacido de la fusión de dos razas, la conquistadora y la conquistada (1951, pp. 19-20, 27)

9 Es bueno resaltar que, en realidad, el fondo del proyecto de la Sociedad Académica de Amantes del País es patriótico y no nacionalista. Véase Quiroz (2014). El nacionalismo criollo en el Mercurio Peruano, en De la Puente (1991). 
al proyecto separatista conforme van adquiriendo conciencia patriótica. Vargas Ugarte aclara que la raza indígena "tuvo un papel secundario en la lucha por la independencia" (1971, p. 80). En la primera nota que añade a la reproducción de la versión de 1801 de la Carta de Viscardo, Vargas Ugarte señala:

El título mismo de la carta nos demuestra que Viscardo ni desconocía ni renuncia a su origen hispánico y comprendía, además, que la emancipación no había de producirse como una reivindicación de la raza indígena ni había de ser obra de ésta sino de los criollos, es decir de los españoles americanos. Los sucesos le dieron la razón, porque en realidad quienes llevaron a cabo la independencia fueron los criollos y los mestizos, sin que esto quiera decir que no se deba conceder alguna participación al elemento indígena. (1971, p. 97, nota 1)

Inclusive, habla de falta de cooperación y hasta traiciones de parte de los indígenas en las rebeliones previas a pesar de que estaba prendiendo el "germen revolucionario", además de la falta de dirección, por ejemplo, en las rebeliones de Túpac Amaru y Mateo Pumacahua, pese a la participación de mestizos dirigidos por José Angulo. Para Vargas Ugarte, la población indígena no estaba preparada, pues "aún estaba lejos el indio de participar [de] las ideas de los americanos y no tenía concepto de la patria". Cambia la situación bajo el liderazgo de los criollos y mestizos, cuando incluso, los indígenas —elemento "conservador por hábito y poco permeable a las nuevas ideas" - van siendo ganados por el patriotismo y hasta harán grandes sacrificios por la libertad (1958, pp. 45-48, 64, 69).

En efecto, Vargas Ugarte muestra una tendencia ascendente en la Independencia. Si con los precursores no se podía alcanzar el éxito, la situación cambia con la llegada de las fuerzas de San Martín. La población mestiza, indígena y esclava ${ }^{10}$ va asumiendo el proyecto separatista conforme adquiere conciencia, siempre bajo la dirección de los criollos. Para él, en junio de 1821 el pueblo de Lima estaba a punto de levantarse en contra del virrey La Serna (1958, p. 286).

Es resaltable la atención que presta Vargas Ugarte a la acción consciente y efectiva de los llamados montoneros y guerrilleros (1958, pp. 228-234, 251-252, 481). Sin embargo, considera a este "verdadero ejército peruano" como grupos auxiliares en toda la campaña separatista en la sierra y costa centrales; es decir, el papel que el ejército "oficial" les dio a estas tropas "irregulares".

Sin ignorar la participación de los extranjeros del sur y del norte, hace énfasis en que fueron los peruanos los protagonistas visibles e invisibles de todo el proceso. Respondiendo a la crítica de José Carlos Mariátegui y adelantándose a versiones muy conocidas posteriormente, Vargas Ugarte afirma que "es conveniente que se conozca lo que el Perú hizo de su parte por obtener la libertad y se disipe la falsa versión de haber logrado nuestro país la independencia merced tan solo a la ayuda de los extraños" (1958, p. 480). En este sentido, el padre Vargas Ugarte crea una versión nacionalista de la independencia peruana.

En efecto, la amplia y fructífera obra de Vargas Ugarte se inicia con la conquista y abarca todo el tiempo de dominación española, la Independencia y la República. Vargas Ugarte da cuenta de una historia de formación de la nación peruana como mestiza, pero conducida hacia sus fines civilizatorios por una élite blanca, occidental, cristiana.

Esta historiografía conservadora, nacionalista y patriota tendrá vigencia en el país en todos los niveles. La tarea de los historiadores era precisar los hechos, descubrir nuevos hechos y protagonistas $y$, así, los nuevos textos $y$, sobre todo, los manuales escolares contenían información muy detallada acerca de los componentes de la Independencia que todo el país debía conocer para poder decir que conocía la historia patria y que la asumía como la historia común de la nación.

Una disidencia muy especial se da cuando historiadores, entonces jóvenes, buscan establecer qué tan independiente fue el accionar de sectores populares durante las luchas separatistas. Dos de los temas que revisan son las rebeliones denominadas precursoras y la participación de las llamadas montoneras y guerrillas en la Independencia. En el primer caso, el centro de atención será la gran rebelión del sur andino de 1780-1783, que se insiste (hasta ahora) en llamarla de Túpac Amaru y separarla en dos supuestas etapas (Bajo y Alto Perú, con Túpac Catari como una suerte de continuador informal del curaca cusqueño).

10 En el caso de la población afroperuana, resalta que, en 1820, por ejemplo, quinientos esclavos se agregaron al ejército sanmartiniano en la hacienda Caucato (Pisco), aunque luego se mencionan solo treinta que fueron apodados los infernales por el gorro rojo que usaban, y luego afirma que los esclavos desertaban para dedicarse a robos (1958, pp. 224, 247, 323 nota 1, 384). No deja de mencionar a mujeres y sacerdotes (1958, p. 232). 
Carlos Daniel Valcárcel dedicó casi toda su vida a conocer el significado de Túpac Amaru en la Independencia. En el segundo caso y, en mucho, bajo la influencia de Valcárcel, Raúl Rivera Serna y Gustavo Vergara Arias buscan establecer qué tanto los pueblos de la sierra y costa centrales del Perú se levantaron de manera autónoma (al margen de la denominada corriente libertadora de San Martín y Bolívar) organizando montoneros y guerrillas.

Sin embargo, no todos estaban de acuerdo. Desde ya, estas versiones pecaban de ser dirigidas a una élite de lectores mientras que a la mayoría de la población se le exigía solo aprender y repetir la información. De ahí proviene el grave desprestigio de la historia en amplios sectores de la población como una disciplina sin mayor conexión con la realidad social, económica, política y cultural del país.

Desde aproximadamente 1940, el país empieza a cambiar de manera muy significativa en distintos aspectos y gracias a diferentes fenómenos. Lo más importante del cambio para los fines de este ensayo es la emergencia de nuevos actores sociales que se abren un camino para lograr espacios propios. El nuevo Perú emergente, producto de migraciones del campo a las ciudades y de la sierra a la costa, tiene otras visiones del país y no le satisface la versión oligárquica de la historia. Inclusive, la rechaza.

Hasta la década de 1950, ser historiador en el Perú implicaba pertenecer de manera directa o adoptada a la élite social. En esas condiciones, los otros sectores sociales interesados en la historia han de ingresar a través de las facultades de Educación. En efecto, uno de los caminos de ascenso social que los provincianos que se trasladan a las ciudades siguen es la docencia. Las escuelas normales son el vehículo para alcanzar un sitial honroso y lograr la capacitación que permita cumplir el apostolado de la docencia en las escuelas rurales y en los pueblos $y$ ciudades del interior.

No perteneciendo, como no pertenecían a la oligarquía, los nuevos maestros del país rechazan la versión de la historia que la oligarquía presenta por no sentirse incluidos y cuestionan el contenido y la forma de conocer la historia con su método memorístico, que obligaba a los alumnos a repetir las listas de gobernantes, sus obras y datos principales como de mucha importancia.
Por su parte, los nuevos sectores sociales tienen reivindicaciones sociales y políticas propias. Abrazan directa o indirectamente las tendencias contestatarias de izquierda y de centroizquierda que buscan acabar con el Perú oligárquico y se alimentan de una historia alternativa a la oficial. Esta historia alternativa es producto tanto de las nuevas tendencias ligadas a la nueva historia y a otras que resaltan lo étnico y popular en la historia con fines reivindicativos. Así como se produce un desborde popular en lo social, también se da un desborde popular en el pensamiento histórico.

La nueva historia proviene de la renovación historiográfica que en todo el mundo sigue a los cambios globales con la derrota de los autoritarismos, las luchas de liberación anticolonial, la opción de la Iglesia por los pobres y las reivindicaciones antimperialistas tras la Segunda Guerra Mundial. La nueva historia social y económica innova en contenidos y enfoques y se presenta como una alternativa a la versión de las élites, y llega al Perú en la década de 1960 y, a pesar del rechazo de la academia formal, se impone en las universidades y centros de investigación (Seminario de Historia Rural Andina de la Universidad de San Marcos, Instituto de Estudios Peruanos, etcétera).

Pero, tan importante como esto, es que el profesor de aula de colegios públicos asume esta innovación y hace de lado el texto escolar (cuando existe), y presenta al alumnado lo que él mismo lee, escucha y discute en charlas, conferencias y cursos de capacitación y actualización. Esta actitud, denominada idea crítica por los sociólogos Gonzalo Portocarrero y Patricia Oliart (1989), es fundamental para entender el rechazo amplio y tal vez generalizado de la población peruana de niveles populares y medios hacia la versión oligárquica de la historia peruana, y es particular su versión de la Independencia cuando en 1971 se conmemoran por todo lo alto los 150 años de la proclamación de la Independencia con la publicación de nuevos estudios y de un corpus documental impresionante por parte de la Comisión Nacional del Sesquicentenario de la Independencia del Perú.

Hacia 1970 no era nueva la idea de que la Independencia no fue un proceso único (unilineal), de consenso (conciencia nacional previa) y con decidida participación y liderazgo de las élites criollas. Ya José Carlos Mariátegui 
la había enunciado en el texto más leído hasta entonces en el Perú. La nueva historia peruana (Pablo Macera) la afirmaba de manera creciente, lo mismo que numerosos historiadores liberales no ligados a la oligarquía historiográfica (Jorge Basadre). Se repetía en aulas, tertulias y textos, con participación de jóvenes historiadores y estudiantes en el convulsionado país de fines de la década de 1960, que afirmaba el carácter solo político de la Independencia y recordaba que las élites criollas habían rechazado la separación incluso luego de la batalla final de Ayacucho en 1824.

Es en ese contexto de la nueva historia económico-social, de las reformas antioligárquicas del régimen militar y de las celebraciones del sesquicentenario de la independencia política en que aparece el ensayo de Heraclio Bonilla y Karen Spalding (1972) cuestionando la importancia que tuvieran los hechos de 1820-1826. Además de negar el carácter propio de la Independencia (la famosa sentencia de la "Independencia"), el ensayo replanteaba la necesidad de estudiar los hechos desde una perspectiva social y económica (y no solo militar y política) teniendo en cuenta tendencias internas, pero subrayando las externas (crisis del régimen español y situación de toda Hispanoamérica) y revisar el papel que cumplieran los precursores tan resaltados por el gobierno militar por conveniencias políticas (Contreras y Glave, 2015).

El éxito que tuviera el ensayo está en que (si bien las ideas eran viejas) la ocasión se presentaba muy propicia: nuevos sectores sociales ávidos de conocer la verdadera historia que los grupos dominantes ocultaban o tergiversaban, la reivindicación de los sectores populares en la historia, nuevas versiones históricas en que se veían reflejados los nuevos actores sociales de la realidad peruana.

El ensayo genera un debate muy álgido debido a que dos jóvenes historiadores no pertenecientes entonces al establishment académico y social arruinaban la fiesta del sesquicentenario y su idea de consagrar la versión oligárquica y nacionalista de la Independencia.

El ensayo no anula la historiografía conservadora, pero sí pone en entredicho el valor de los estudios anteriores ${ }^{11}$. A partir de entonces, historiadores liberales y progresistas, $y$, sobre todo, las nuevas generaciones de historiadores y estudiosos de la sociedad han de dirigir sus esfuerzos hacia la validación de las tesis de Bonilla-Spalding y hacia la resolución de problemas ligados a la sociedad, a la economía, a la cultura, a las regiones, y también a los hechos políticos y militares de la Independencia.

No es casual que las dos efemérides siguientes fueran asumidas con mayor sentido crítico en nuestra historiografía. En efecto, el bicentenario de la gran rebelión del sur andino, de 1780-1783, y el centenario de la guerra con Chile (1979) fueron motivo de un renovado interés por el planteamiento de nuevos problemas de investigación más que por la publicación de documentos históricos. No es necesario hacer una relación de los trabajos de historia que aparecen con motivo de esas celebraciones, pero sí señalar que los estudios impulsaron el conocimiento y nuevas interpretaciones.

\section{Bicentenario}

Si bien es discutible el carácter separatista de Túpac Amaru, esto no nos obliga a cuestionar el carácter anticolonial de todo el movimiento en sus diversas tendencias sociales y étnico-culturales. En todo caso, la rebelión de 1814-1817 sí es claramente separatista, pero tuvo el defecto de no haber sido liderada por criollos, criollos de Lima, sino por mestizos e indígenas provincianos, además de ser generadora de un nuevo desborde de violencia popular y étnica.

Dicho esto, no debe extrañar que en el Perú no hayamos reclamado con mayor énfasis y contundencia que nuestro bicentenario no es el último en Hispanoamérica, sino el primero. Ni siquiera el bicentenario de la otra rebelión del sur andino, la de los hermanos Angulo y Mateo Pumacahua (1814-1817) generó un interés nacional ${ }^{12}$.

No es difícil concluir que el Perú ha cambiado muchísimo en el último medio siglo, desde el sesquicentenario. Es un nuevo país, aunque siempre se tendrá discusiones acerca de la medida en que se trata de un país enteramente

11 En realidad, la historiografía conservadora (Ilamada impropiamente tradicional) se mantiene hasta el día de hoy en sus postulados originales en torno a la Independencia, aunque con metodologías novedosas ligadas al denominado retorno a la narrativa, a la historia cultural y a la nueva historia política y conceptual.

12 Cuando en el 2014 desarrollamos el VI Congreso Nacional de Historia en el Cusco, nos dimos cuenta de que los intelectuales locales habían celebrado solo la actuación de los hermanos Angulo, rechazando la parte correspondiente a Mateo Pumacahua, como a alguien que merecía ser "borrado de la foto" por haber sido el "traidor" de 1780 y el oportunista de 1814. El hecho muestra lo siguiente: a) se mantiene la idea de la Independencia hecha por los criollos y mestizos, y b) se mantiene la idea de que la Independencia del Perú se produjo en 1821 y todo lo anterior sigue siendo considerado solo como precursores. 
moderno. Lo más importante para nuestro propósito se refiere a si el país tiene un destino como nación impuesto por sectores sociales dirigentes o se maneja según los vaivenes de intereses de grupos solo dominantes.

Lo concreto es que la historiografía peruana era vista como extremadamente pesimista a inicios de la década de 1990 en medio de la guerra contra Sendero Luminoso y el Movimiento Revolucionario Túpac Amaru (MRTA) y la enorme crisis económica, social y política de entonces. Sectores pudientes cuestionan las ideas de un país fracasado en su trayectoria y buscan nuevas historias que impriman optimismo a la población. La gran tarea es controlar los discursos históricos y eso pasa por crear los textos escolares obligatorios escritos y revisados por el Ministerio de Educación para eliminar el monopolio del saber y de interpretar la historia que tenían los profesores (en buena medida, simpatizantes o militantes de grupos de izquierda).

No es posible hablar de una sola tendencia en la historiografía $\mathrm{y}$, antes bien, nuestra historiografía ratifica su ancestral carácter conflictivo. La nueva tendencia conservadora ve la historia peruana en positivo en medio de un auge neoliberal exportador de minerales y de grandes obras de infraestructura que imprime optimismo económico y social al país.
La Independencia está en el centro de las discusiones por la cercanía del bicentenario. La exigencia de ser vista como positiva está ligada a igualarse a las historiografías de países vecinos que han aprovechado las celebraciones de sus bicentenarios remarcando el momento fundacional de sus propias nacionalidades. Para esto, es claro que se presenta el hecho militar como una gesta gloriosa, pero también muy fructífera en cambios que no dudan en denominar revolucionarios. El Perú, parece decirse, no puede quedar como el país que inicia su vida independiente y republicana con la vergüenza de no haber querido dar el paso y, al darlo, busca cambiar lo menos posible las estructuras políticas, sociales, económicas y culturales.

Como en todo, lo más probable es que la verdad se encuentre alejada de los extremos. Se requiere superar la visión que rechaza las iniciativas propias en la Independencia, pero también aquella que las afirma de manera contundente. Un tema central es ver la diversidad del proceso separatista al conocer la realidad regional y local, y también conocer mejor la participación de los sectores sociales que nos hemos acostumbrado a llamar como criollos, indios, mestizos, negros y castas, y no según las identidades sociales que tenían.

\section{Referencias}

Bonilla, H., y Spalding, K. (1972). La independencia del Perú: la palabra y los hechos. En La Independencia en el Perú. Lima: Instituto de Estudios Peruanos / Ediciones Campodónico.

Carrasco-Limas, A. (1954). La Historia del Perú de Juan Basilio Cortegana. Una contribución al estudio de la historia nacional. Lima:Tipografía Peruana.

HeRreRA, B. (1846). Sermón pronunciado por el doctor don Bartolomé Herrera, rector del Colegio de San Carlos, el día 28 de julio de 1846 aniversario de la independencia del Perú. Lima: Imprenta administrada por L. Herrera.

LORENTE, S. (1879). Historia de la civilización peruana. Lima: Imprenta liberal administrada por M. Fernández.

LORENTE, S. (2005 [1876]). Escritos fundacionales de historia peruana [compilación y estudio introductorio: Mark Thurner]. Lima: COFIDE / Universidad Nacional Mayor de San Marcos.

VALDEZ Y PALACIOS, J.-M. (1971). Bosquejo sobre el estado político, moral y literario del Perú en sus tres grandes épocas. Lima: Biblioteca Nacional del Perú.

VARGas UGarte, R. (1958). Historia del Perú. Emancipación (1809-1825). Buenos Aires: Imprenta López.

Vargas Ugarte, R. (1971). La Carta a los Españoles Americanos de Viscardo y Guzmán. Lima: CMB Ediciones. 


\section{Bibliografía}

BELAÚNDE, V.-A. (1942). Peruanidad. Elementos esenciales. Lima: Editorial Lumen.

BeLAúNDE, V.-A. (1987) Obras completas. Lima: Comisión Nacional del Centenario (6 tomos).

Bueno, C. (1763). Catálogo histórico de los virreyes, gobernadores, presidentes y capitanes generales del Perú, con los sucesos más principales de sus tiempos. El Conocimiento de los Tiempos.

CASALINO SEn, C.-A. (2008). Los héroes patrios y la construcción del Estado-nación en el Perú (siglos xix y xx) (tesis de doctorado). Universidad Nacional Mayor de San Marcos.

Cerdán-de-Landa y Simón-Pontero, A. [Nerdacio]. (1791-1795). Disertación preliminar a los apuntamientos históricos de los más principales hechos y acaecimientos de cada uno de los señores gobernantes, presidentes y virreyes del Perú, con producción del extracto de sus relaciones de gobierno, y de otros documentos antiguos inéditos, para desempeñar el artículo 16 del plan de materias publicado en el Mercurio Peruano por el señor don... En Mercurio Peruano 339-342, X, 215-244.

Contreras, C., y Glave, L.-M. (Eds.). (2015). La independencia del Perú. ¿Concedida, conseguida, concebida? Lima: Instituto de Estudios Peruanos.

Córdova y UrRutia, J.-M. (1844 [1845]). Las tres épocas del Perú o compendio de su historia. Lima: Imprenta del Autor.

LORENTE, S. (1866). Historia del Perú, compendio para el uso de los colegios y de las personas ilustradas. Lima: Aubert \& Loiseau.

MARIÁTEGUI, J.-C. (1928 [1989]). 7 ensayos de interpretación de la realidad peruana. Lima: Biblioteca Amauta.

Paz SoldÁn, M. F. (1868-1874). Historia del Perú independiente. Lima: Imprenta de El Nacional/Le Havre: Imprenta de Alfonso Lemale (3 tomos).

Portocarrero, G., y Oliart, P. (1989). El Perú desde la escuela. Lima: Instituto de Apoyo Agrario.

Riva Agüero y Osma, José-De-LA-. (1938). El Inca Garcilaso de la Vega. En Por la verdad, la tradición y la patria (opúsculos) (pp. 3-53). Lima: Torres Aguirre.

Rosas LaURo, C. (2005). La reivindicación de la memoria. Los incas en los periódicos de Lima y Cusco, de la colonia a la república. En Luis Millones (Ed.), Ensayos de historia andina (pp. 119-152). Lima: Universidad Nacional Mayor de San Marcos, Fondo Editorial de la Facultad de Ciencias Sociales.

SANDERS, K. (1997). Nación y tradición. Cinco discursos en torno a la nación peruana, 1885-1930. Lima: Instituto Riva Agüero, Pontificia Universidad Católica del Perú.

UnANUE, J. H. (1985). Guía política, eclesiástica y militar del Virreynato del Perú para el año de 1793. Lima: Corporación Financiera de Desarrollo. 